\title{
Melatonin rhythms in renal transplant recipients with sleep-wake disturbances
}

\section{Hanna Burkhalter, Sabina De Geest, Anna Wirz-Justice \& Christian Cajochen}

To cite this article: Hanna Burkhalter, Sabina De Geest, Anna Wirz-Justice \& Christian Cajochen (2016) Melatonin rhythms in renal transplant recipients with sleep-wake disturbances, Chronobiology International, 33:7, 810-820, DOI: 10.3109/07420528.2016.1169192

To link to this article: http://dx.doi.org/10.3109/07420528.2016.1169192

\section{6.}

\section{ए马} Submit your article to this journal $\square$

\section{Щ Article views: 158}

Q View related articles ¿

View Crossmark data ¿`

Citing articles: 1 View citing articles $\square$ 


\title{
Melatonin rhythms in renal transplant recipients with sleep-wake disturbances
}

\author{
Hanna Burkhalter ${ }^{\mathrm{a}, \mathrm{b}}$, Sabina De Geest ${ }^{\mathrm{b}, \mathrm{c}}$, Anna Wirz-Justice ${ }^{\mathrm{d}}$, and Christian Cajochen ${ }^{\mathrm{d}}$ \\ ${ }^{a}$ Centre for Sleep Medicine, Hirslanden Group, Zürich, Switzerland; 'bnstitute of Nursing Science, University of Basel, Basel, Switzerland; \\ 'Academic Center for Nursing and Midwifery, KU Leuven, Belgium; 'Centre for Chronobiology, Psychiatric Hospital of the University of Basel, \\ Basel, Switzerland
}

\begin{abstract}
We assessed salivary melatonin levels in renal transplant (RTx) recipients who participated in a randomised, multicentre wait-list controlled trial on the effect of bright light therapy on their sleep and circadian rhythms. A large proportion of RTx recipients in our cohort had unexpectedly low melatonin values, which precluded calculation of the dim-light melatonin onset (DLMO) as a circadian marker. Thus, the aim of this post hoc analysis was to describe the melatonin profile of home-dwelling RTx recipients diagnosed with sleep-wake disturbances (SWDs). The participants were characterised by means of sleep questionnaires, validated psychometric instruments [Pittsburgh sleep quality Index (PSQI), Epworth sleepiness scale (ESS), Morningness-Eveningness Questionnaire (MEQ) and Depression, Anxiety and Stress Scale (DASS)] in addition to melatonin assay in saliva. Data were analysed with descriptive statistics and group comparisons made with appropriate post hoc tests. RTx recipients $[n=29$ (aged $54.83 \pm 13.73$, transplanted $10.62 \pm 6.84$ years ago)] were retrospectively grouped into two groups: RTx recipients whose dim light melatonin onset (DLMO) could be calculated $(n=11)$ and those whose DLMO could not be calculated $(n=18)$. RTx recipients having a measurable DLMO had a number of differences from those without DLMO: they were younger [46.4 \pm 14.9 compared to $60.0 \pm 10.3(p=.007)$ ], had higher haemoglobin values $[135.36 \pm 12.01$ versus $122.82 \pm 11.56(p=.01)]$, less anxiety $[4(0 ; 8)$ versus $12(6.5 ; 14)(p=.021)$ ] and a better overall sense of coherence [SOC Score: $71.09 \pm 12.78$ versus $56.28 \pm 15.48(p=0.013)$ ]. These results suggest that RTx recipients whose DLMO could be calculated have less health impairments, underlying the relevance of a stable circadian system.
\end{abstract}

\section{KEYWORDS}

Adults; chronobiology; kidney transplantation; melatonin profile; rental transplant recipients; sleep-wake disturbances; salivary melatonin

\section{Introduction}

The purpose of the main study was to evaluate the feasibility of implementing a daily morning bright light therapy intervention in renal transplant (RTx) recipients with sleep disturbances, in the community setting, and to conduct a preliminary exploration of its efficacy for improving sleep characteristics (Burkhalter et al., 2015).

The sleep-wake cycle is one of many circadian rhythms driven by the biological clock located in the suprachiasmatic nuclei and synchronised to the 24-hour day by daylight (Vitaterna et al., 2001). Sleep-wake disturbances (SWDs) are actual or perceived changes in sleep resulting in daytime impairment. Poor sleep quality $(30.7 \%)$ and poor daytime functioning (34.1\%) affect many RTx patients (Burkhalter et al., 2011). In the general population, poor sleep is positively associated with obesity (Cappuccio et al., 2008), heart disease
(Cappuccio et al., 2011), type 2 diabetes (Cappuccio et al., 2010) and depression (Alvaro et al., 2013). RTx recipients are already at risk for these factors [cancer (Wong \& Chapman, 2008); coronary heart disease (Israni et al., 2010), diabetes, dyslipidemia, hypertension (Lodhi et al., 2011), depression (Rosenberger et al., 2005)] due to lifelong immunosuppressive therapy and fear of acute or chronic rejection (Lodhi et al., 2011) .

Endogenous melatonin levels are normally low during the day, increase in the evening, peak in the middle of the night and gradually fall during the second half of the night (Nagtegaal et al., 1998). The increase in melatonin secretion in the evening correlates with an increase in sleep propensity (Uchiyama et al., 2002). Thus, the endogenous melatonin rhythm exhibits a close association with the endogenous circadian component of the sleep propensity rhythm. This has led to the idea 
that melatonin is an internal sleep "facilitator" in humans (Cajochen et al., 2003). Melatonin is also a key factor initiating a thermoregulatory cascade which decreases heat production and induces vasodilatation of distal skin regions leading to heat loss, which in turn increases sleepiness and decreases core body temperature preparatory for sleep (Kräuchi et al., 2006). The evening melatonin rise represents an established marker for circadian phase in clinical settings when the entire nocturnal rhythm cannot be measured. Thus, the dim-light melatonin onset (DLMO) is a standardised estimate of circadian phase when samples are collected under dim light conditions to avoid suppression of synthesis (Lewy \& Sack, 1989).

Saliva for melatonin assay is often self-collected and stored at home with reliable results (Keijzer et al., 2011). Measurement interference can arise from bleeding gums (Pullman et al., 2012), toothpaste (Figueiro \& Rea, 2010), caffeine, tobacco and alcohol (Hartter et al., 2006; Zhou et al., 2009) leading to erratic values. Further, benzodiazepines (Hajak et al., 1996; McIntyre et al., 1988; McIntyre et al., 1993), beta blockers (Scheer et al., 2012; Stoschitzky et al., 1999; Vijayasarathy et al., 2010), nonsteroidal anti-inflammatory drugs (Murphy et al., 1996), anticoagulants (Zhou et al., 2009), diabetes medications (Nagorny \& Lyssenko, 2012) and oral contraceptives (Hilli et al., 2008) have been associated with low melatonin values.

Melatonin secretion declines with age (Sack et al., 1986) and growth (Bojkowski \& Arendt, 1990; Griefahn et al., 2003). People with hormone cycle dysfunction, damaged melatonin receptors (fragile $\mathrm{X}$ syndrome), disease-induced night-day rhythm reversal (e.g. Smith-Magenis Syndrome, a developmental disorder), or calcification of the pineal gland (Kunz et al., 1999; Mahlberg et al., 2009) require up to $100 \%$ melatonin supplementation (Van Thillo et al., 2010). People with a melatonin deficiency or disruption have an increased prevalence of sleep disorders (Haimov et al., 1994) and sleep-wake cycle disturbances (Pandi-Perumal et al., 2005). However, patients after pinealectomy did not have major sleep disturbances (Macchi \& Bruce, 2004). Thus, normal daily melatonin profiles may contribute to sleep problems but not necessarily determine them, and their functional significance is unclear (Macchi \& Bruce, 2004).
Based on the overview of possible mechanisms of desynchronisation of sleep-wake rhythms, leading to sleep disturbances in dialysis patients (Parker, 2003) and in patients with chronic kidney disease (Russcher et al., 2012), we assume similar mechanisms for RTx recipients. The only significant finding in the intervention group after bright light therapy, applied each morning to regularise nocturnal sleep, was a phase advance in both get-up time and bedtime in the actimetry data (Burkhalter et al., 2015). However, only very few participants had a measureable DLMO, which precluded documenting any parallel advance in DLMO after morning light therapy. We therefore performed a post hoc analysis of the baseline database of saliva melatonin profiles to elucidate any clinical differences between $\mathrm{RTx}$ recipients with and without a DLMO. The aim of this study was to descriptively explore relevant variables associated with low respectively no melatonin secretors for future melatonin analysis in RTx recipients and in other chronic diseases.

\section{Material and methods}

This descriptive analysis was based on the baseline data of a multicentre randomised wait-list controlled design study (Burkhalter et al., 2015). The intervention group completed 3 weeks of baseline measurement, followed by 3 weeks of morning bright light therapy, then a 3-week post-treatment assessment. The baseline assessment for the control group had a 9-week duration, followed by 3 weeks of morning bright light therapy.

\section{Participants, eligibility criteria and setting}

Participants were recruited at the University Hospitals of Basel, Berne and Zurich and had all participated in a screening study to evaluate sleep disorders in these patients (Burkhalter et al., 2013; Burkhalter et al., 2014). The inclusion criteria were adult RTx recipients more than 1 year post-transplant and diagnosed with SWD (sleep assessment interview in the preceding study); German speaking; on stable immunosuppressive drugs and no signs of acute rejection. Thirty were recruited; one dropped out. Baseline conditions were the same for the intervention and the control groups. 


\section{Measures}

\section{Clinical characteristics}

Clinical characteristics [age in years, gender, years since transplantation, BMI $\left(\mathrm{kg} / \mathrm{m}^{2}\right)$, blood creatinine, haemoglobin, blood urea nitrogen and the Charlson Comorbidity Index] were retrieved from the participants' hospital medical charts. Sleep quality (Pittsburgh Sleep Quality Index: PSQI), daytime sleepiness (Epworth Sleepiness Scale: ESS), depression, anxiety and stress symptomatology (Depression, Anxiety and Stress Scale: DASS-21), seasonal depression (Personal Inventory for Depression and Seasonal Affective Disorder: PIDS-SA), sense of coherence (Sense of Coherence: SOC-13 (Antonovsky, 1993)), physical activity (Godin Leisure-Time Exercise Questionnaire: GLTEQ (Godin \& Shephard, 1985)), chronotype (Morningness-Eveningness Questionnaire) and the sleep measurements (assessment questionnaire) were retrieved from our previous observational study data bank (Burkhalter et al., 2011; Burkhalter et al., 2013; Burkhalter et al., 2014). A high sense of coherence reflects an attitude of confidence that life events (e.g. pain, illness, sleep disturbance...) (1) are structured, predictable and explicable; (2) the resources are available to one to respond to this life event and (3) and that this situation is a challenge that is worth investment and engagement (Antonovsky, 1993).

\section{Melatonin profiles}

To determine melatonin values, participants collected saliva samples using Salivettes (Sarstedt AG, Sevelen, Switzerland) and were asked to do this under dim home lighting conditions. They collected saliva on day 1 of baseline, the final day of BLT and the final day of the study. For each 24-h collection period, participants collected and refrigerated up to five samples at 1-h intervals, starting $5 \mathrm{~h}$ before predicted bedtime and ending at bedtime, as well as night-time samples should they wake up, and then a series after wake time and 3 during the day. Melatonin was measured via direct double-antibody radioimmunoassay (analytical sensitivity: $0.2 \mathrm{pg} / \mathrm{ml}$ ) and a functional minimum detectable dose of 0.65 $\mathrm{pg} / \mathrm{ml}$ (Bühlmann Laboratories AG, Allschwil, Switzerland)(Weber et al., 1997). Salivary melatonin is normally below $3 \mathrm{pg} / \mathrm{ml}$ during the daytime and up to $10 \mathrm{pg} / \mathrm{ml}$ at bedtime (Altpeter et al., 2006), with broad individual variability in maximum secretion (peak values: 2-84 pg/ml) (Burgess \& Fogg, 2008). To determine a DLMO at least five salivary melatonin measures are needed and at least one sample has to show a significant concentration elevation compared to daytime samples. The DLMO was estimated by an objective "hockey stick" method developed for sensitivity and reliability (Danilenko et al., 2014).

The phase angle describes the relationship between the timing of the biological clock and the timing of external cues (Emens et al., 2009). The phase angle between the DLMO and sleep onset time was calculated by subtracting the DLMO time from the patient's bedtime.

\section{Data collection}

The current study was approved by the relevant ethics committees of Basel, Bern and Zurich. Data were collected from December 2010 until September 2012 and details are described in the main study (Burkhalter et al., 2015).

\section{Statistical analysis}

We used descriptive statistics including means, standard deviations (SDs), medians, quartiles, frequencies, cross-tabulations and graphs to uncover any data anomalies, such as missing values, outliers or extreme values, as well as the variables under study to determine their levels of measurement and data distributions. The Mann-Whitney $\mathrm{U}$ test and Phi tests (for nominal or dichotomous variables) and independent $t$-tests were used to explore differences between groups. The level of significance was set at $p<0.05$. SPSS 22 Statistics software (Version 22.0.0, IBM Corporation, Armonk, New York, United States) was used for statistical analysis.

\section{Results}

Almost two-thirds of the patients had extremely low or unmeasurable melatonin levels. Thus, RTx recipients $[n=29$ (aged $54.8 \pm 13.7$, transplanted $10.6 \pm 6.8$ years ago)] were separated retrospectively into two groups: RTx recipients whose DLMO could be calculated $(n=11)$ and those whose 
DLMO could not $(n=18)$. Table 1 shows the sample characteristics of the two groups. Figure 1 shows the saliva melatonin profile over night. The mean DLMO was similar to a healthy population: $21.7 \mathrm{~h} \pm 0.95$ versus $20.1 \pm 1.1$ (morning types) and $21.7 \mathrm{~h} \pm 0.95$ versus $22.0 \pm 1.2$ (evening types) (Emens et al., 2009), but the phase angle of DLMO to bedtime was shorter than in this healthy population: $1.2 \pm 1.5$ hversus $2.2 \pm 1.1$ (morning types) and $1.2 \pm 1.5$ hversus $1.6 \pm 1.1$ (evening types) (Emens et al., 2009; Lewy et al., 2006).

RTx recipients having a measurable DLMO had a number of differences from those without DLMO: they were younger $[46.4 \pm 14.90$ compared to $60.0 \pm$ $10.3(p=.007)]$, had higher haemoglobin values $[135.36 \pm 12.01$ versus $122.82 \pm 11.56(p=.01)]$, less anxiety $[4(0 ; 8)$ versus $12(6.5 ; 14)(p=.021)]$ and a better overall sense of coherence [(SOC score $71.09 \pm 12.78$ versus $56.28 \pm 15.48(p=.013)]$. There were also tendencies to lower BMI [23.21 \pm 4.06 versus $27.14 \pm 5.58(p=0.053)]$, to have better blood urea nitrogen values $[6.36 \pm 1.23$ versus $8.49 \pm 3.51(p=0.064)]$, less stress $[8(4 ; 16)$ versus $15(9 ; 30) p=0.076]$, better subjective sleep efficiency [(PSQI $77.0 \pm 16.37$ versus $61.55 \pm 24.81(p=.078)$ ], fewer sleep interruptions $[2(2 ; 3)$ versus $3(2 ; 3.25)$ $p=0.084$ ], less difficulty waking up [ $22 \%$ versus $54 \%$ $(p=0.076)]$, be less tired $[2(1 ; 3)$ versus $3(2 ; 4)$ $p=0.092]$ and demonstrate higher comprehensibility (a belief that life events are happening because of a reason) [SOC Comprehensibility score: $26.55 \pm$ 5.85 versus $22.56 \pm 5.91(p=0.088)]$. However, fewer had a kidney from a living donor [ $18 \%$ versus $44 \% p=0.093$ ].

Further descriptive differences (n.s.) between RTx recipients with and without DLMO were: less sleep medication (9.1\% versus $33.3 \%$ ), fewer beta blockers (27.3\% versus $44.4 \%)$, half had $100 \%$ employment (54.4\% versus $27.7 \%$ ) and they showed a lower chance to doze off during the day $(9.1 \%$ versus $22.2 \%)$. The perceived sleep latency was shorter (27.45 min versus $55.17 \mathrm{~min}$ ) and the sleep duration as well (5.29 $\mathrm{h}$ versus $5.94 \mathrm{~h}$ ).

Figure 1 shows that the DLMO group had fewer nocturnal wake-up saliva samples (n.s.). It is also clear from the figure that the individuals without DLMO also had low melatonin throughout the night, whereas the DLMO group also showed the characteristic morning decline after waking.

\section{Discussion}

To our knowledge, this is the first study describing saliva melatonin profiles in RTx recipients with SWDs. Our results suggest that RTx recipients whose DLMO could be calculated have less health impairments, underlying the relevance of a stable circadian system. Melatonin amplitude and melatonin rhythm have been shown to decrease in chronic kidney disease patients with advancing renal dysfunction (Koch et al., 2010). There is only one study of $23 \mathrm{RTx}$ recipients with saliva melatonin measurements at preTx and 3 months post-Tx (Russcher et al., 2015). Although melatonin values were low in this study, the DLMO was always calculable. The main difference to our study was that we only included patients with poor sleep quality and daytime sleepiness, while Russcher et al. also included patients with good sleep quality and no daytime sleepiness.

\section{Low saliva melatonin values}

Since we had 2-4 melatonin evening profiles for each patient throughout the study (data not shown), the presence of consistently low values or consistently normal values provided reliability, i.e. that these were not an artefact of non-adherence to the study (e.g. toothpaste, using electronic devices that emit melatonin-suppressing blue light). There is now a long tradition of studying home-collected melatonin samples with good reliability; we can therefore assume that our participants correctly collected saliva samples.

Low saliva melatonin values in $\mathrm{RTx}$ recipients might arise from different causes. First of all, there was a 13.6-year age difference between the groups, and it is known that melatonin secretion declines with age (Pandi-Perumal et al., 2005). However, our analysis with respect to age did not explain the relevant melatonin differences between the groups (significant for younger age were the expected variables such as taking fewer beta blockers, later DLMO, working 100\%, suffering sleep difficulties, more impairment following sleep problems, more difficulty to wake up and lower sense of coherence).

In daytime haemodialysis patients an absence (Karasek et al., 2005) in the nocturnal rise in melatonin concentration has been reported (Koch et al., 2009) probably due to the dialysis itself. Very 
Table 1. Demographics, clinical data, psychosocial and sleep characteristics of 29 renal transplant recipients with sleep disorders.

\begin{tabular}{|c|c|c|c|c|c|}
\hline & & $N=11(\mathrm{DLMO})$ & & & \\
\hline & $N=29$ & Mean \pm SD & $N=18($ no DLMO) & & \\
\hline DLMO (decimal time) & & $21.7 \pm 0.95$ & & & \\
\hline Phase angle DLMO to bedtime (h) & & $1.2 \pm 1.5$ & & & \\
\hline Demographics & Per cent & Per cent & Per cent & Phi/Kruskall/T & $p$ Value \\
\hline \multirow[t]{2}{*}{$\operatorname{Men}^{\mathrm{a}}$} & 51.7 & 54.5 & 50.0 & 0.044 & 0.812 \\
\hline & Mean \pm SD & Mean \pm SD & Mean \pm SD & $T$-test & $p$ Value \\
\hline Age (years) $^{\mathrm{a}}$ & $54.8 \pm 13.7$ & $46.4 \pm 14.9$ & $60.0 \pm 10.3$ & -2.924 & 0.007 \\
\hline $\mathrm{BMI}^{\mathrm{a}}$ & $25.6 \pm 5.3$ & $23.2 \pm 4.1$ & $27.1 \pm 5.6$ & -2.026 & 0.053 \\
\hline $100 \%$ work $^{c}$ & 37.9 & 54.5 & 27.7 & 0.268 & 0.149 \\
\hline Clinical & Median & Median & Median & & Mann-Whitney U test \\
\hline \multirow[t]{2}{*}{ Charlson Comorbidity Index ${ }^{a}$} & $1(0 ; 2)$ & $2(0 ; 2)$ & $1(0 ; 2)$ & & 0.746 \\
\hline & Mean & Mean & Mean & $T$-test & $p$ Value \\
\hline Years since $\mathrm{RT}^{\mathrm{a}}$ & $10.6 \pm 6.8$ & $11.2 \pm 8.1$ & $10.3 \pm 6.2$ & 0.34 & 0.737 \\
\hline Creatinine $(\mu \mathrm{mol} / \mathrm{l})^{\mathrm{a}}$ & $115.5 \pm 47.4$ & $106.8 \pm 34.6$ & $121.1 \pm 54.3$ & -0.771 & 0.448 \\
\hline Haemoglobin $(\mathrm{g} / \mathrm{l})^{\text {a }}$ & $127.7 \pm 13.1$ & $135.4 \pm 12.0$ & $122.8 \pm 11.6$ & 2.761 & 0.01 \\
\hline \multirow[t]{2}{*}{ Blood Urea Nitrogen $(\mathrm{mmol} / \mathrm{l})^{a}$} & $7.7 \pm 3.00$ & $6.4 \pm 1.2$ & $8.5 \pm 3.5$ & -1.933 & 0.064 \\
\hline & Per cent & Per cent & Per cent & Phi/Kruskall/T & $p$ Value \\
\hline Taking beta blocker ${ }^{a}$ & 37.9 & 27.3 & 44.4 & 0.172 & 0.355 \\
\hline Taking sleep medications ${ }^{c}$ & 24.1 & 9.1 & 33.3 & 0.275 & 0.139 \\
\hline Had a living graft donor ${ }^{a}$ & 34.5 & 18.2 & 44.4 & 0.324 & 0.093 \\
\hline Sleep & Mean \pm SD & Mean \pm SD & Mean \pm SD & $T$-test & $p$ Value \\
\hline Sleep quality (PSQI Score) ${ }^{b}$ & $12.2 \pm 3.6$ & $10.9 \pm 3.7$ & $12.9 \pm 3.4$ & -1.508 & 0.143 \\
\hline Sleep efficiency $(\%)^{\mathrm{b}}$ & $67.4 \pm 23.0$ & $77.0 \pm 16.4$ & $61.5 \pm 24.8$ & 1.83 & 0.078 \\
\hline \multirow[t]{2}{*}{ Sleep latency $(\mathrm{min})^{c}$} & $44.7 \pm 52.9$ & $27.4 \pm 19.0$ & $55.1 \pm 63.9$ & -1.392 & 0.175 \\
\hline & Median & Median & Median & & Mann-Whitney U test \\
\hline Sleep interruptions ${ }^{c}$ & $2(1 ; 3)$ & $1(1 ; 3)$ & $3(2 ; 3.25)$ & & 0.084 \\
\hline \multirow[t]{2}{*}{ Tiredness ${ }^{\mathrm{c}}$} & $3(2 ; 4)$ & $2(1 ; 3)$ & $3(2 ; 4)$ & & 0.092 \\
\hline & Mean & Mean & Mean & $T$-test & $p$ Value \\
\hline Sleep latency after interruption $(\min )^{c}$ & $31.1 \pm 42.6$ & $36.4 \pm 52.0$ & $27.8 \pm 36.9$ & 0.517 & 0.609 \\
\hline Sleep duration $(\mathrm{h})^{\mathrm{c}}$ & $5.7 \pm 1.7$ & $5.3 \pm 1.5$ & $5.9 \pm 1.8$ & -0.989 & 0.332 \\
\hline Daytime & Mean \pm SD & Mean \pm SD & Mean \pm SD & $T$-test & $p$ Value \\
\hline \multirow[t]{2}{*}{ Daytime sleepiness (ESS Score) $^{b}$} & $7.7 \pm 3.7$ & $7.2 \pm 3.7$ & $8.1 \pm 3.8$ & -0.605 & 0.55 \\
\hline & Per cent & Per cent & Per cent & Phi/Kruskall/T & $p$ Value \\
\hline Have difficulties to wake up ${ }^{c}$ & 34.5 & 54.5 & 22.2 & 0.33 & 0.076 \\
\hline High chance to doze off ${ }^{c}$ & 17.2 & 9.1 & 22.2 & 0.64 & 0.732 \\
\hline Have impaired daytime functioning ${ }^{c}$ & 48.3 & 45.5 & 50 & 0.44 & 0.812 \\
\hline Psychosocial & Mean \pm SD & Mean \pm SD & Mean \pm SD & $T$-test & $p$ Value \\
\hline SOC Score ${ }^{b}$ & $61.9 \pm 16.0$ & $71.1 \pm 12.8$ & $56.3 \pm 15.5$ & 2.663 & 0.013 \\
\hline SOC Comprehensibility ${ }^{b}$ & $24.1 \pm 6.1$ & $26.5 \pm 5.8$ & $22.6 \pm 5.9$ & 1.77 & 0.088 \\
\hline SOC Manageability ${ }^{\mathrm{b}}$ & $17.2 \pm 4.9$ & $19.1 \pm 4.5$ & $16.1 \pm 5.1$ & 1.611 & 0.119 \\
\hline SOC Meaningfulness ${ }^{b}$ & $18.8 \pm 5.4$ & $20.6 \pm 4.2$ & $17.6 \pm 5.9$ & 1.491 & 0.148 \\
\hline MEQ Score ${ }^{b}$ & $55.8 \pm 10.8$ & $53.9 \pm 12.5$ & $56.9 \pm 9.8$ & -0.729 & 0.472 \\
\hline \multirow[t]{2}{*}{ GLTEC Score ${ }^{b}$} & $38.3 \pm 24.4$ & $42.4 \pm 19.9$ & $35.8 \pm 27.0$ & 0.693 & 0.494 \\
\hline & Median & Median & Median & & Mann-Whitney U test \\
\hline DASSD $^{b}$ & $10(2 ; 20)$ & $4(2 ; 14)$ & $16(2 ; 24.5)$ & & 0.159 \\
\hline DASSA $^{b}$ & $8(2 ; 13)$ & $4(0 ; 8)$ & $12(6.5 ; 14)$ & & 0.021 \\
\hline DASSS $^{\mathrm{b}}$ & $14(6 ; 18)$ & $8(4 ; 16)$ & $15(9 ; 30)$ & & 0.076 \\
\hline PIDS Score ${ }^{b}$ & $3(1.5 ; 5)$ & $3(0 ; 3)$ & $3.5(1.75 ; 6)$ & & 0.188 \\
\hline SAD Score ${ }^{b}$ & $7(3 ; 9.5)$ & $5(1 ; 8)$ & $7(3.75 ; 10.5)$ & & 0.276 \\
\hline
\end{tabular}

${ }^{\mathrm{a}}$ Medical charts; ${ }^{\mathrm{b}}$ Survey study $1 ;{ }^{\mathrm{C}}$ Sleep questionnaire study 2.

$\mathrm{SD}=$ standard deviation; DLMO = dim-light melatonin onset; PSQI = Pittsburgh Sleep Quality Index; ESS = Epworth Sleepiness Scale; SOC = Sense of Coherence; GLTEC = Godin Leisure-Time Exercise Questionnaire; MEQ = Morningness-Eveningness Questionnaire; DASS = Depression Anxiety and Stress Scale; PIDS = Personal Inventory for Depression; SAD = Seasonal Affective Disorder Questionnaire. 
(a)
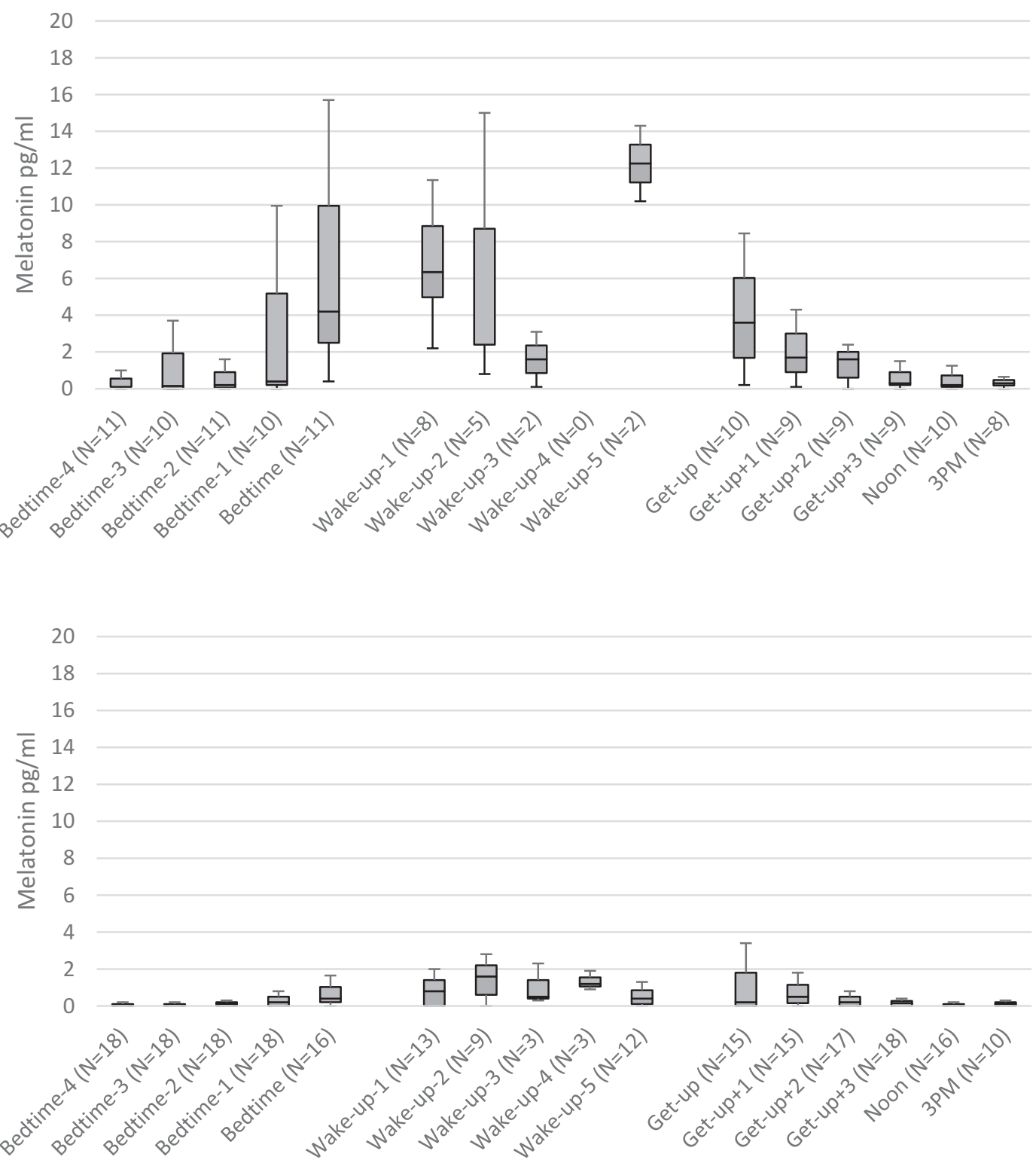

(b)

Figure 1. Saliva melatonin profile among (a) RTx recipients with a DLMO and (b) RTx recipients without a DLMO . In brackets at each time point are the actual number of individuals. The sleep period was between bedtime and get-up. The usual cut-off for DLMO with this assay is $3 \mathrm{pg} / \mathrm{ml}$. Wake-up measures represent saliva samples taken during nocturnal awakenings. Plots are median and interquartile range.

low values were also found (Koch et al., 2010) in chronic kidney failure patients significantly correlating with failure degree (Koch et al., 2010). Our sample however was stable with regard to kidney function (we excluded patients with acute rejection or hospitalisation) and had good renal function.

Eleven of the participants were taking beta blockers, which may diminish melatonin synthesis (Stoschitzky et al., 2006). However, 3 out of 11 patients taking beta blockers were in the DLMO group. Thus, since only 8 of the 18 patients with non-calculable DLMO took beta blockers; this may not be the main reason for the observed low melatonin values in the no-DLMO group. This corroborates findings in haemodialysis patients (Koch et al., 2009) where beta blockers did also not explain low melatonin values. Another reason for low melatonin could relate to the calcification of the pineal gland (Kunz et al., 1999), since a characteristic of chronic kidney disease is high vascular calcification. Multiple risk factors, such as high calcium and phosphorus burden, abnormal 
bone metabolism, impaired renal excretion and medication, induce vascular smooth muscle cells to change into chondrocyte or osteoblast-like cells (Moe \& Chen, 2008).

Further, the DLMO group had a prior health disadvantage: Table 1 shows that fewer patients in the DLMO group had a kidney from a living donor, yielding a worse health condition pre-Tx (Pippias et al., 2015). Longer pre-transplant dialysis duration is associated with poorer outcome in kidney-transplanted patients (Remport et al., 2011). If a partner, parents or friends are willing to donate a kidney, the patient in need can plan the transplantation early in the disease course and might avoid haemodialysis. Pre-emptive transplantation (avoiding haemodialysis) is associated with higher patient survival and improved quality of life (Jay et al., 2015).

\section{Is low melatonin an indicator for worse health?}

Besides haemodialysis patients, we are not aware of any patient group that has such a high percentage of low or no melatonin secretors. It may be related to the transplantation itself, or to the long-term treatment following transplantation (e.g. side effects of immunosuppressants and oxidative stress). RTx recipients whose DLMO was uncalculable were older, but not more ill in view of comorbidities (e.g. the Charlson Comorbidity Index was even lower in this group). However, in view of health, this group had lower haemoglobin that could be associated with iron deficiency and anaemia. Lower haemoglobin values are not associated with older age (Hawkinset al., 1954). Anaemia is a risk factor for cardiovascular complication in RTx recipients (Mix et al., 2003). They had higher urea values (showing a decrease of kidney function) further, they had a higher BMI that is a risk factor for cardiovascular diseases. This group also had fewer resources to cope and fewer resources effective in avoiding or combating a range of psychosocial stressors. This is shown in the lower sense of coherence score (the lower the score, the fewer available coping resources to face life-stress experience) and in the higher scores of anxiety and stress symptomatology.

The fewer nocturnal wake-up saliva samples in the DLMO group suggest a sounder sleep (Figure 1). Additionally, the characteristic morning decline after waking in the DLMO group is another confirmation of a sound circadian rhythm in this patient group. Patients having an SWD and showing no DLMO may be at a higher risk for other illnesses (Hardeland et al., 2012). For these reasons we suggest that RTx recipients who have measurable melatonin rhythms may suffer less health impairment, thus supporting the relevance of a stable circadian system.

\section{Clinical relevance}

The meaurement of salivary DLMO cannot be performed routinely in RTx recipients, neither would this be recommended. Instead, routine assessment of selfreported sleep quality and daytime sleepiness should be performed regularly with a simple visual analogue scale (Burkhalter et al., 2011). The detection of poor sleep quality and/or excessive daytime sleepiness should prompt a sleep assessment (Burkhalter et al., 2013) with a sleep diary or an actimeter (objective data). Thereafter, sleep hygiene rules should be encouraged, including regular sleep-wake schedules, exposure to bright light in the early hours of the morning (e.g. a 30-minute walk outdoors) and avoidance of bright light exposure (particularly the blue screens of electronic devices) in the evening (Stepanski \& Wyatt, 2003). If there is no improvement with these behavioural interventions, a diagnostic clarification could help through measurement of salivary DLMO (Bühlmann Laboratories AG, Allschwil, Switzerland - www.buhlmannlabs.ch).

Therefore, instead of prescribing sleeping pills, it might be useful to first try melatonin supplementation for those without melatonin secretion in the evening. Melatonin supplementation $(3 \mathrm{mg})$ at 22:00 pm has shown good results in haemodialysis patients. Melatonin supplementation recovered the low nocturnal melatonin rise of these patients and improved sleep fragmentation, sleep onset latency and subjective sleep quality (Koch et al., 2009). All efforts targeting a high nocturnal melatonin and intact melatonin signalling are in favour of avoiding various illnesses (Hardeland, 2012) and keeping a well-synchronised sleep-wake cycle.

Melatonin deficiency has been associated with prostate, endometrial and breast cancer (Hardeland, 2012). RTx recipients are at 2.5- to 3.9-fold higher risk for cancer compared to genral population 
(Janus et al., 2012). This is therefore an additional reason to measure salivary DLMO.

Melatonin induces beneficial effects at numerous pathophysiological levels related to chronic kidney disease both under experimental (Quiroz et al., 2008) and clinical conditions (Hrenak et al., 2015). It has been suggested that melatonin supplementation is beneficial in neurodegenerative disorders, by protecting brain cells from oxidative stress (Miller et al., 2015). These results are promising in view that transplanted kidneys are prone to oxidative stress-mediated injury by pre-transplant and posttransplant conditions that cause reperfusion injury or imbalance between oxidants and antioxidants (Nafar et al., 2011). An animal study has even proposed to supplement patients taking tacrolimus (one of the most often used immunosuppressive drugs in RTx recipients) with melatonin. Further clinical and experimental studies are needed, as the administration of melatonin might protect the livers of tacrolimus-treated patients by reducing the severity of oxidative stress and increasing the levels of antioxidant enzymes (Karabulut \& Ara, 2009).

\section{Conclusion}

Assessing and treating SWDs in RTx recipients could be relevant for improving clinical outcome. This study originally investigated 926 RTx recipients (Burkhalter et al., 2014), of whom 21.3\% reported daytime sleepiness (ESS > 10) and 58.6\% reported poor sleep quality (PSQI $>5$ ); 249 RTx recipients participated in a sleep survey and 164 RTx participated in the subsequent sleep assessment to determine a preliminary sleep disorders diagnosis (Burkhalter et al., 2013); 49 had a putative diagnosis of SWD, of whom 30 participated in the bright light intervention study (Burkhalter et al., 2015). Within this latter group a high majority had low or no melatonin rhythm. These results suggest that $\mathrm{RTx}$ recipients without melatonin rhythms have more health impairments.

\section{Strengths and limitations}

Strengths of this study included our use of salivary melatonin samples to objectively estimate circadian rhythms with the DLMO. Here we found highly reproducible individual melatonin data when comparing 2-4 profiles. In addition to the melatonin curves, many self-reported questionnaires and clinical data gave a broad insight into this population.

Limitations of this study were the post hoc nature of the analysis. The study was not designed based on a theoretical framework. This led to a conservative analysis, focussing on descriptive results. We performed additional statistical tests to minimise Type I Error and to detect whether significant correlations could be explained by the age difference of the two groups, which it did not. Future full-powered studies sould be aware of the statistical limitation we had with such a small sample size. An additional limitation was that our study assessed drugs by groups and not substance classes (e.g. we had a category beta blockers but did not distinguish between beta 1-selective blockers (atenolol, bisoprolol), non-selective beta blocker (propranolol) and vasodilatator beta blockers (carvedilol and nebivolol). Therefore, the three RTx recipients who had a DLMO might have been taking carvedilol or nedivolol which does not suppress melatonin (Scheer et al., 2012; Wyatt et al., 2006).

\section{Acknowledgments}

This study was funded by a research grant from the Swiss Renal Foundation (Alfred and Erika Baer-Spycher Foundation). We thank Claudia Renz, Centre for Chronobiology, University Psychiatric Clinics Basel and Bühlmann AG for the melatonin assays.

\section{Declaration of interest}

The results presented in this study have not been published elsewhere. The authors report no conflicts of interest. The authors alone are responsible for the content and writing of the paper.

\section{References}

Altpeter ES, Roosli M, Battaglia M, Pfluger D, Minder CE, Abelin T. (2006). Effect of short-wave (6-22 MHz) magnetic fields on sleep quality and melatonin cycle in humans: The Schwarzenburg shut-down study. Bioelectromagnetics. 27:142-50.

Alvaro PK, Roberts RM, Harris JK. (2013). A systematic review assessing bidirectionality between sleep disturbances, anxiety, and depression. Sleep. 36:1059-68. 
Antonovsky A. (1993). The structure and properties of the sense of coherence scale. Soc Sci Med. 36:725-33.

Bojkowski CJ, Arendt J. (1990). Factors influencing urinary 6-sulphatoxymelatonin, a major melatonin metabolite, in normal human subjects. Clin Endocrinol (Oxf). 33:435-44.

Burgess HJ, Fogg LF. (2008). Individual differences in the amount and timing of salivary melatonin secretion. PLoS One. 3:e3055.

Burkhalter H, Brunner DP, Wirz-Justice A, Cajochen C, Weaver T, Steiger J, Fehr T, Venzin RM, De Geest S. (2013). Self-reported sleep disturbances in renal transplant recipients. BMC Nephrol. 14:1-12.

Burkhalter H, Sereika SM, Engberg S, Wirz-Justice A, Steiger J, De Geest S. (2011). Validity of 2 sleep quality items to be used in a large cohort study of kidney transplant recipients. Prog Transpl. 21:27-35.

Burkhalter H, Wirz-Justice A, Cajochen C, Weaver TE, Steiger J, Fehr T, Venzin RM, De Geest S. (2014). Daytime sleepiness in renal transplant recipients is associated with immunosuppressive non-adherence: A crosssectional, multi-center study. Clin Transplant. 28:58-66.

Burkhalter H, Wirz-Justice A, Denhaerynck K, Fehr T, Steiger J, Venzin RM, Cajochen C, Weaver TE, De Geest S. (2015). The effect of bright light therapy on sleep and circadian rhythms in renal transplant recipients: A pilot randomized, multicentre wait-list controlled trial. Transpl Int. 28:59-70.

Cajochen C, Krauchi K, Wirz-Justice A. (2003). Role of melatonin in the regulation of human circadian rhythms and sleep. J Neuroendocrinol. 15:432-37.

Cappuccio FP, Cooper D, D'Elia L, Strazzullo P, Miller MA. (2011). Sleep duration predicts cardiovascular outcomes: A systematic review and meta-analysis of prospective studies. Eur Heart J. 32(12):1484-1492.

Cappuccio FP, D’Elia L, Strazzullo P, Miller MA. (2010). Quantity and quality of sleep and incidence of type 2 diabetes: A systematic review and meta-analysis. Diabetes Care. 33:414-20.

Cappuccio FP, Taggart FM, Kandala NB, Currie A, Peile E, Stranges S, Miller MA. (2008). Meta-analysis of short sleep duration and obesity in children and adults. Sleep. 31:619-26.

Danilenko KV, Verevkin EG, Antyufeev VS, Wirz-Justice A, Cajochen C. (2014). The hockey-stick method to estimate evening dim light melatonin onset (DLMO) in humans. Chronobiol Int. 31:349-55.

Emens JS, Yuhas K, Rough J, Kochar N, Peters D, Lewy AJ. (2009). Phase angle of entrainment in morning- and evening-types under naturalistic conditions. Chronobiol Int. 26:474-93.

Figueiro MG, Rea MS. (2010). The effects of red and blue lights on circadian variations in cortisol, alpha amylase, and melatonin. Int. J. Endocrinol. 2010:829351.

Godin G, Shephard RJ. (1985). A simple method to assess exercise behavior in the community. Can J Appl Sport Sci. 10:141-46.

Griefahn B, Brode P, Blaszkewicz M, Remer T. (2003). Melatonin production during childhood and adolescence: A longitudinal study on the excretion of urinary 6-hydroxymelatonin sulfate. J Pineal Res. 34:26-31.

Haimov I, Laudon M, Zisapel N, Souroujon M, Nof D, Shlitner A, Herer P, Tzischinsky O, Lavie P. (1994). Sleep disorders and melatonin rhythms in elderly people. BMJ. 309:167.

Hajak G, Rodenbeck A, Bandelow B, Friedrichs S, Huether G, Ruther E. (1996). Nocturnal plasma melatonin levels after flunitrazepam administration in healthy subjects. Eur Neuropsychopharmacol. 6:149-53.

Hardeland R. (2012). Neurobiology, pathophysiology, and treatment of melatonin deficiency and dysfunction. Sci World J. 2012:640389.

Hardeland R, Madrid JA, Tan DX, Reiter RJ. (2012). Melatonin, the circadian multioscillator system and health: The need for detailed analyses of peripheral melatonin signaling. J Pineal Res. 52:139-66.

Hartter S, Korhonen T, Lundgren S, Rane A, Tolonen A, Turpeinen M, Laine K. (2006). Effect of caffeine intake 12 or 24 hours prior to melatonin intake and CYP1A2*1F polymorphism on CYP1A2 phenotyping by melatonin. Basic Clin Pharmacol Toxicol. 99:300-04.

Hawkins WW, Speck E, Leonard VG. (1954). Variation of the hemoglobin level with age and sex. Blood. 9:999-1007.

Hilli J, Korhonen T, Turpeinen M, Hokkanen J, Mattila S, Laine K. (2008). The effect of oral contraceptives on the pharmacokinetics of melatonin in healthy subjects with CYP1A2 g.-163C>A polymorphism. J Clin Pharmacol. 48:986-94.

Hrenak J, Paulis L, Repova K, Aziriova S, Nagtegaal EJ, Reiter RJ, Simko F. (2015). Melatonin and renal protection: Novel perspectives from animal experiments and human studies (review). Curr Pharm Des. 21:936-49.

Israni AK, Snyder JJ, Skeans MA, Peng Y, Maclean JR, Weinhandl ED, Kasiske BL, Investigators P. (2010). Predicting coronary heart disease after kidney transplantation: Patient Outcomes in Renal Transplantation (PORT) Study. Am J Transplant. 10:338-53.

Janus N, Launay-Vacher V, Ferrero JM, Thariat J. (2012). Risk of cancer in patients following chronic dialysis and kidney graft. Bull Cancer. 99:285-93.

Jay CL, Dean PG, Helmick RA, Stegall MD. (2015). Reassessing preemptive kidney transplantation in the United States: Are we making progress? Transplantation. Epub ahead of print.

Karabulut AB, Ara C. (2009). Melatonin ameliorates tacrolimus (FK-506)'s induced immunosupressive effect in rat liver. Transplant Proc. 41:1875-77.

Karasek M, Szuflet A, Chrzanowski W, Zylinska K, Swietoslawski J. (2005). Decreased melatonin nocturnal concentrations in hemodialyzed patients. Neuro Endocrinol Lett. 26:653-6.

Keijzer H, Smits MG, Peeters T, Looman CW, Endenburg SC, Gunnewiek JM. (2011). Evaluation of salivary melatonin measurements for Dim Light Melatonin Onset calculations in patients with possible sleep-wake rhythm disorders. Clin Chim Acta. 412:1616-20.

Koch BC, Nagtegaal JE, Hagen EC, van der Westerlaken MM, Boringa JB, Kerkhof GA, Ter Wee PM. (2009). The effects of 
melatonin on sleep-wake rhythm of daytime haemodialysis patients: A randomized, placebo-controlled, cross-over study (EMSCAP study). Br J Clin Pharmacol. 67:68-75.

Koch BC, van der Putten K, Van Someren EJ, Wielders JP, Ter Wee PM, Nagtegaal JE, Gaillard CA. (2010). Impairment of endogenous melatonin rhythm is related to the degree of chronic kidney disease (CREAM study). Nephrology, Dialysis, Transplantation: Off Publ Eur Dialysis Transplant Assoc - Eur Renal Assoc. 25:513-19.

Kräuchi K, Cajochen C, Pache M, Flammer J, Wirz-Justice A. (2006). Thermoregulatory effects of melatonin in relation to sleepiness. Chronobiol Int. 23:475-84.

Kunz D, Schmitz S, Mahlberg R, Mohr A, Stoter C, Wolf KJ, Herrmann WM. (1999). A new concept for melatonin deficit: On pineal calcification and melatonin excretion. Neuropsychopharmacol. 21:765-72.

Lewy AJ, Lefler BJ, Emens JS, Bauer VK. (2006). The circadian basis of winter depression. Proc Natl Acad Sci U S A. 103:7414-19.

Lewy AJ, Sack RL. (1989). The dim light melatonin onset as a marker for circadian phase position. Chronobiol Int. 6:93-102.

Lodhi SA, Lamb KE, Meier-Kriesche HU. (2011). Solid organ allograft survival improvement in the United States: The long-term does not mirror the dramatic short-term success. Am J Transplant. 11:1226-35.

Macchi MM, Bruce JN. (2004). Human pineal physiology and functional significance of melatonin. Front Neuroendocrinol. 25:177-95.

Mahlberg R, Kienast T, Hadel S, Heidenreich JO, Schmitz S, Kunz D. (2009). Degree of pineal calcification (DOC) is associated with polysomnographic sleep measures in primary insomnia patients. Sleep Medicine. 10:439-45.

McIntyre IM, Burrows GD, Norman TR. (1988). Suppression of plasma melatonin by a single dose of the benzodiazepine alprazolam in humans. Biol Psychiatry. 24:108-12.

McIntyre IM, Norman TR, Burrows GD, Armstrong SM. (1993). Alterations to plasma melatonin and cortisol after evening alprazolam administration in humans. Chronobiol Int. 10:205-13.

Miller E, Morel A, Saso L, Saluk J. (2015). Melatonin redox activity. Its potential clinical applications in neurodegenerative disorders. Curr Top Med Chem. 15:163-69.

Mix TC, Kazmi W, Khan S, Ruthazer R, Rohrer R, Pereira BJ, Kausz AT. (2003). Anemia: A continuing problem following kidney transplantation. Am J Transplant. 3:1426-33.

Moe SM, Chen NX. (2008). Mechanisms of vascular calcification in chronic kidney disease. J Am Soc Nephrol. 19:213-6.

Murphy PJ, Myers BL, Badia P. (1996). Nonsteroidal antiinflammatory drugs alter body temperature and suppress melatonin in humans. Physiol Behav. 59:133-9.

Nafar M, Sahraei Z, Salamzadeh J, Samavat S, Vaziri ND. (2011). Oxidative stress in kidney transplantation: Causes, consequences, and potential treatment. Iran J Kidney Dis. 5:357-72.

Nagorny C, Lyssenko V. (2012). Tired of diabetes genetics? Circadian rhythms and diabetes: The MTNR1B story? Curr Diab Rep. 12:667-72.
Nagtegaal JE, Kerkhof GA, Smits MG, Swart AC, Van Der Meer YG. (1998). Delayed sleep phase syndrome: A placebo-controlled cross-over study on the effects of melatonin administered five hours before the individual dim light melatonin onset. J Sleep Res. 7:135-43.

Pandi-Perumal SR, Zisapel N, Srinivasan V, Cardinali DP. (2005). Melatonin and sleep in aging population. Exp Gerontol. 40:911-25.

Parker KP. (2003). Sleep disturbances in dialysis patients. Sleep Med Rev. 7:131-43.

Pippias M, Stel VS, Areste-Fosalba N, Couchoud C, Fernandez-Fresnedo G, Finne P, Heaf JG, Hoitsma A, De Meester J, Palsson R, Ravani P, Segelmark M, Traynor JP, Reisaeter AV, Caskey FJ, Jager KJ. (2015). Long-term kidney transplant outcomes in primary glomerulonephritis: Analysis from the ERA-EDTA registry. Transplantation. Epub ahead of print.

Pullman RE, Roepke SE, Duffy JF. (2012). Laboratory validation of an in-home method for assessing circadian phase using dim light melatonin onset (DLMO). Sleep Medicine. 13:703-6.

Quiroz Y, Ferrebuz A, Romero F, Vaziri ND, RodriguezIturbe B. (2008). Melatonin ameliorates oxidative stress, inflammation, proteinuria, and progression of renal damage in rats with renal mass reduction. Am J Physiol Renal Physiol. 294:F336-44.

Remport A, Keszei A, Vamos EP, Novak M, Jaray J, Rosivall L, Mucsi I, Molnar MZ. (2011). Association of pre-transplant dialysis duration with outcome in kidney transplant recipients: A prevalent cohort study. Int Urol Nephrol. 43:215-24.

Rosenberger J, Geckova AM, Dijk JP, Roland R, Heuvel WJ, Groothof FJ. (2005). Factors modifying stress from adverse effects of immunosuppressive medication in kidney transplant recipients. Clin Transplant. 19:70-6.

Russcher M, Koch B, Nagtegaal E, van der Putten K, ter Wee P, Gaillard C. (2012). The role of melatonin treatment in chronic kidney disease. Front Biosci (Landmark Ed). 17:2644-56.

Russcher M, Nagtegaal JE, Nurmohamed SA, Koch BC, van der Westerlaken MM, van Someren EJ, Bakker SJ, Ter Wee PM, Gaillard CA. (2015). The effects of kidney transplantation on sleep, melatonin, circadian rhythm and quality of life in kidney transplant recipients and living donors. Nephron. 129:6-15.

Sack RL, Lewy AJ, Erb DL, Vollmer WM, Singer CM. (1986). Human melatonin production decreases with age. J Pineal Res. 3:379-88.

Scheer FA, Morris CJ, Garcia JI, Smales C, Kelly EE, Marks J, Malhotra A, Shea SA. (2012). Repeated melatonin supplementation improves sleep in hypertensive patients treated with beta-blockers: A randomized controlled trial. Sleep. 35:1395-1402.

Stepanski EJ, Wyatt JK. (2003). Use of sleep hygiene in the treatment of insomnia. Sleep Med Rev. 7:215-25.

Stoschitzky K, Sakotnik A, Lercher P, Zweiker R, Maier R, Liebmann P, Lindner W. (1999). Influence of beta-blockers on melatonin release. Eur J Clin Pharmacol. 55:111-5. 
Stoschitzky K, Stoschitzky G, Brussee H, Bonelli C, Dobnig H. (2006). Comparing beta-blocking effects of bisoprolol, carvedilol and nebivolol. Cardiology. 106:199-206.

Uchiyama M, Shibui K, Hayakawa T, Kamei Y, Ebisawa T, Tagaya H, Okawa M, Takahashi K. (2002). Larger phase angle between sleep propensity and melatonin rhythms in sighted humans with non-24-hour sleep-wake syndrome. Sleep. 25:83-88.

Van Thillo A, Devriendt K, Willekens D. (2010). Sleep disturbances in Smith-Magenis syndrome: Treatment with melatonin and beta-adrenergic antagonists. Tijdschr Psychiatr. 52:719-23.

Vijayasarathy K, Shanthi Naidu K, Sastry BK. (2010). Melatonin metabolite 6-sulfatoxymelatonin, $\mathrm{Cu} / \mathrm{Zn}$ superoxide dismutase, oxidized LDL and malondialdehyde in unstable angina. Int J Cardiol. 144:315-17.
Vitaterna MH, Takahashi JS, Turek FW. (2001). Overview of circadian rhythms. Alcohol Res Health: J National Inst Alcohol Abuse Alcoholism. 25:85-93.

Weber J, Schwander J, Unger I, Meier D. (1997). A direct ultrasensitive RIA for the determination of melatonin in human saliva: Comparison with serum levels. Sleep Res. 26:757.

Wong G, Chapman JR. (2008). Cancers after renal transplantation. Transplant Rev. 22:141-9.

Wyatt JK, Dijk DJ, Ritz-de Cecco A, Ronda JM, Czeisler CA. (2006). Sleep-facilitating effect of exogenous melatonin in healthy young men and women is circadian-phase dependent. Sleep. 29:609-18.

Zhou SF, Zhou ZW, Yang LP, Cai JP. (2009). Substrates, inducers, inhibitors and structure-activity relationships of human Cytochrome P450 2C9 and implications in drug development. Curr Med Chem. 16:3480-675. 